\title{
Articles
}

\section{Information Anxiety and African-American Students in a Graduate Education Program}

\author{
By Patricia Fields Katopol
}

\begin{abstract}
Library anxiety has been cited as one factor affecting academic performance, but library use is only part of obtaining information for academic needs. This paper expands the concept of library anxiety to information anxiety by an examination of the information behavior of black graduate students when using a variety of information resources, including electronic and human. Findings indicate that information anxiety is a continuous element of minority students' information behavior and creates a barrier to obtaining and using information for academic work.
\end{abstract}

Sonya, an accomplished young black woman, tentatively approached the reference desk and asked her question about the work of a certain black scholar. "I've never heard of her. Did you look in this database?" suggested the librarian. Sonya shook her head. She wasn't aware of the database and wouldn't have known how to search it if she had known about it. She was surprised the librarian wasn't familiar with the scholar, whom Sonya had thought was rather well-known. For her part, the librarian looked at Sonya and wondered why this grad student didn't know about a database that practically everyone used. This wasn't the first time Sonya felt uneasy when working with a librarian. She wondered what was wrong with her; maybe she wasn't graduate school material after all?

Perhaps a librarian can be forgiven for assuming that graduate students, having successfully maneuvered their way through an undergraduate program, would know the basics of library research. But could it be that graduate students have problems satisfying their information needs? Could it be possible that they are as anxious about obtaining information as their undergraduate counterparts?

This study explores the information behavior of graduate students in education, in particular, black graduate students in a majority institution, that is, a university at which Caucasians are in the majority. It examines how these students obtain information needed for academic work, their problems in obtaining this information, and their perception of race and information acquisition and sharing. Importantly, it expands the notion of "library anxiety" to one of information anxiety as it considers the variety of information sources used by graduate students.

\section{Motivation}

Currently, almost a third of the population of the United States of America is considered a minority. Almost half will be a minority in 2042 (U.S. Census, 2008). As of the 2010 Census, blacks were 13 percent of the population (U.S. Census, 2011). Similar statistics exist for other minorities. For example, Hispanics were 16 percent as of the 2010 Census (U.S. Census, 2011), but will increase to 20.1 percent by 2050 (U.S. Census, 2009). Our colleges and universities already reflect the changing population; however, despite entering higher education at increased rates, the retention and graduation rates for black graduate students is low, so that even after ten years in a graduate program, only $47 \%$ of black students obtain their doctoral degree (Council of Graduate Schools, 2008). Once they have completed the course work portion of the graduate program, students often lose their ties to faculty and other students and are on their own as they complete other degree requirements. This study was motivated by a need to inquire if and how 
information behaviors affected graduate students at this stage of their degree studies.

\section{The Study}

The study reframes ideas about library anxiety by expanding the sources of information sought by students to include electronic and human, as well as print. These sources may be provided as part of library services or may lie outside of the library's control. The study seeks to ascertain student feelings and behavior surrounding information activities and also addresses the perceived effect of race on information behavior such as retrieval and sharing. It considers academic activities as 'work,' and examines these activities using a methodological framework appropriate for examining information behavior in the workplace.

\section{Method}

The exploratory, qualitative study uses Cognitive Work Analysis (CWA) (Rasmussen, Pejtersen, \& Goodstein, 1994; Vicente, 1999; Pettigrew, Fidel, \& Bruce, 2001), a methodological framework that examines cognitive behavior with a focus on the constraints faced by actors in the workplace as they perform knowledge work, that is, work that requires information and decision-making based on the information acquired. As defined by CWA, constraints are factors outside of the actor's control, but which affect the actor's information behavior. They determine what an actor can and cannot do within the system and are neither positive nor negative. For example, a departmental budget can be a constraint: it can cause spending to be restricted and decrease travel grants but is also the source of funding for faculty, facilities, and student jobs.

Participants included fewer than ten graduate students from various concentrations in the education program at a large university in the American Midwest. Students were at the comprehensive exam, thesis, or dissertation stage. The study was limited to participants at this stage of the process as these students are more likely to require large amounts of specialized information and may need to obtain them outside of the support of a course structure.
Participants were recruited via an Institutional Review Board (IRB)-approved request made through the broadcast email service of a black student organization. The message included information that the researcher's race was the same as prospective participants to encourage them to feel comfortable participating in a study that included interview questions on attitudes about race.

Questions in the structured, open-ended interview were framed to elicit responses regarding numerous sources of information used by participants. These sources of information included human (such as librarians, other students, or professors); electronic resources (such as the library website, databases, social networking and push technology sources, or non-library internet sources); and physical library resources (for example, books and journals available only in print). Participants were asked to recount their information behavior while performing a specific task related to the comprehensive exam, thesis, or dissertation process. Finally, participants were questioned as to their perceptions of race and information behavior.

\section{Findings}

The interview responses revealed four significant aspects of participant information behavior: tasks, search, use of electronic media, and perceptions of race.

Tasks

Participants were asked to recall specific tasks that were part of their work as graduate students. These tasks included information search and retrieval for papers, creating reading lists for comprehensive exams, finding information for their advisor, and deciding on dissertation topics. They wrote papers, graded assignments as part of their teaching duties, and gave formal and informal presentations on their research or readings. Primarily, tasks were constrained by the time available to do them, such as the end of the semester. Time constraints were usually determined by something or someone other than the participant, such as the academic calendar or 
an advisor, but could also be created by work and family demands. Participants stated that time constraints created problems as they sought to balance multiple tasks with similar time constraints, such as producing multiple course papers that were all due at the end of term, or prioritizing dissimilar tasks such as grading homework as part of their teaching assistant duties while working on their own homework assignments or meeting an employer's deadline. According to participants, it was time, rather than the nature of the task, that often determined the effort spent and the number of resources used when searching for information. Participants sometimes smiled when admitting that time was the primary determinative of the effort of they made when working on information tasks and noted that they were uncomfortable with that, but felt that limiting the time for information tasks was the only way they could manage all of their work.

\section{An Anxious Search}

Participants felt anxious or lost when engaged in the information search. Either they found too much information, so that they spent a lot of time determining relevance, or not enough information, so that they spent time searching through scant sources in an attempt to find enough information to complete the task. Searches were performed without the assistance of library staff. Participants reached out to other students for information, both for content and process. Those in the exam phase sought students who had taken comprehensive exams the year before. Others sought students who were working on projects similar to their own. They stated that although they would have preferred to go to their professors for this information, professors were often unavailable, either due to other commitments or to what students interpreted as an attempt to help them become independent researchers and learn the literature on their own. Even when professors met with students, participants stated that it was common for them to offer few suggestions for relevant literature. Students said that they understood the need to learn about the discipline, but that being left on their own made information tasks difficult. For example, when guidance was not provided, participants spent more time looking for information, trying to ascertain if they had enough information, and hoping that what they found would be acceptable to the professor. They found it difficult to end their search while they remained unsure of what the professor required.

\section{Wary Users of Electronic Media}

Participants were frequent users of electronic media and rarely visited the library. The infrequent trips to the library were due mostly to time constraints; a preference for the electronic format, which could be accessed from anywhere, at anytime, and easily printed out if needed; and a belief that the librarian would not be helpful for their particular information needs. While they did not visit the physical library, participants did make frequent use of the library website, from several times a week to several times a day. They did this mostly to access journal databases and individual journal articles. Rather than use the search function of the various databases, they used Google and Google Scholar to search for an article and then accessed it from the library website. Participants stated that they often came across websites with discipline-related information that appeared useful, but which required them to evaluate the site for authenticity and veracity. They felt confident in their abilities to judge the authenticity of information on those sites, basing this confidence on knowledge of the literature in their domain--for example, if they came across a familiar author or reference, they were more inclined to treat the site as trustworthy. They also used electronic information services such as listservs and wikis created for academics, students, and practitioners in their discipline. The most frequent reason for using non-library resources and websites was that the library did not carry resources relevant to their research needs. This typically occurred when students were looking for research on blacks or created by black scholars, but also happened because the library didn't carry a particular journal. 


\section{Race and Information Behavior}

All participants perceived race as a negative factor in their search for information. The majority believed that librarians had no knowledge of their racially-related research interests and therefore could not help them with their information needs. They also believed that white students had separate access to information, provided to them by majority faculty and based on a shared racial background. Participants uniformly stated a belief that they had to have more information than their white counterparts in order to be taken seriously. This belief was held by all participants and mentioned spontaneously during the interview. Similarly, when the actions or attitudes of whites were explicitly mentioned, it was in terms of a belief that they had more access to information than did black students, that white professors gave white students more information because they formed closer relationships with them, and even if the parties didn't mean to exclude students of color from the information, such exclusion was bound to occur (according to participants). Students also said it was necessary to filter people's comments and actions - it was hard to know who was a friend or who had their best interests at heart.

There was a concern that retrieved information would be viewed as insufficient or inadequate by other students and professors. This made information sharing, such as leading a discussion, difficult and added another layer of discomfort to the experience, above and beyond the nerves or anxiousness that might normally accompany such an assignment. Students stated that while it was often difficult for them to fill their information needs, they believed that this was not a problem for white students because their research tended to focus on issues common to or typical for the majority population--which there was a great deal of easily accessible, existing research. They also stated that white students can be unwilling to share their resources with black students. To deal with this perceived lack of information sharing, participants discussed their information dilemmas with other black graduate students from different departments, and used these students, rather than "official" information sources such as librarians, professors, and administrative staff, as resources for information on such topics as useful databases, the job market, or university procedures.

\section{Discussion}

As developed by Constance Mellon (1986), the term library anxiety refers to student anxiety or fears regarding the library (Katopol, 2005). These fears can range from being afraid to interrupt the librarian while $\mathrm{s} / \mathrm{he}$ is at the reference desk, to an inability to negotiate the library's physical structure, to a belief that other classmates were familiar with the library and its resources, while they themselves were not. Students with library anxiety may also avoid the reference librarian out of a fear that the librarian may judge the student as incompetent. Library anxiety is not the exclusive province of the undergraduate, but can also be present in graduate students who may avoid feelings of discomfort by putting off work that requires a visit to the library, or procrastinate on projects and assignments (Onwuegbuzie \& Jiao, 1997 and 2000). Stress avoidance as manifested by students can mean that they do not ask for assistance from the librarian when needed so that they do not learn about sources that would help them with their academic information needs. Graduate students with perfectionist tendencies will also exhibit some form of library anxiety due to the conflicts inherent in trying to control their academic work (where they can exhibit perfectionism) and their inability to successfully navigate and use the library. Finally, Jiao and Onwuegbuzie (1998) hypothesized that library anxiety may be an important element as to why a significant portion of graduate students do not complete their degrees due to failure to complete their thesis or dissertation, which usually requires extensive use of library resources and a high level of library expertise.

Although the concept of library anxiety is a useful start, it has limited application for today's student, who has many options for information retrieval outside of the physical structure of the library. First, students have always obtained information for academic activities by talking to people such as their professors, other students, and university 
administrators. Second, the existence of journal databases and e-books enables students to retrieve these resources anywhere the student has online access. Trips to the library can be avoided, especially in disciplines that rely heavily on journals and conference proceedings, resources that are more likely to be available online. More and more older journals can be accessed remotely via databases such as JSTOR, so that many students may rarely need to visit the library during their entire academic career. Third, the internet contains many authoritative sites from universities, think tanks, government, and nonprofit organizations that students may use with confidence. Individual researchers and professors may maintain their own authoritative web sites. None of these sources require that the student enter the library.

The concept of information anxiety is more relevant to the information behavior of students when we consider these sources in the aggregate. It focuses on what students are actually doing, fulfilling an information need, rather than where they do it. The mental stress surrounding information activities and filling information needs should be labeled as such, since the goal is obtaining information, which may or may not include visiting the library. In addition, framing the problem as information anxiety allows the concept to be examined in other contexts and for other populations, such as the elderly, the chronically ill, or people at work, populations that may or may not use the library to meet information needs.

\section{Problems in Information Anxiety}

Upon examination of the findings, one cause of information anxiety for these students is the need to work in an atmosphere in which information is hoarded. This can be seen where professors fail to provide information about comprehensive exams, so that the student has to find out this very important information from other students and where professors refuse to provide adequate guidelines for information retrieval so that students do not know what information the professor wants and how the retrieved information will be regarded. One participant captured the effect of this failure to assist with a basic task, such as having a paper reviewed by a faculty member:

"Because it's not valued enough,
it's not worthy of your [the
professor's] attention, it's not
worthy of you editing my paper
because it's about a population
that is beneath you. And then you
try and convince me to pick a
different population. No. And
then that becomes something that
you use against me. And now you
make it seem like I'm wasting
your time and forcing you to read
a paper about some minorities
that you don't want to read about,
so that's why you don't want to
help me with my research, 'cause
it's about minorities. And it's
been more than one student
who's had that issue."

If the student can't count on faculty for help, the student is likely to go elsewhere for assistance; unfortunately, "elsewhere" rarely includes the library or librarian.

\section{Anyone but the Librarian}

Information search and retrieval tasks become problematic if students are uncomfortable going to librarians to meet these needs. From one participant, "[y]ou're at a point where you're not finding stuff. It gets a little stressful when you're trying to decide what you need to look at and a lot of times you're just influenced by what you've already found." This student was not going to the librarian for help, but struggling alone. That the student is influenced by what was previously found is particularly important: this student, like others in the study, used what was familiar, even if they thought the source might not have all the information they needed for the task.

Participants were of two minds when it came to librarians. First, they thought a librarian was only 
useful for locating materials or suggesting a journal. All of the participants turned first to Google Scholar in their search for relevant literature, then perhaps to one of the university library's journal databases. None of the comments suggested that students knew that a librarian could offer assistance by suggesting new approaches or assisting with the unfamiliar jargon of a new discipline as a student worked through an information problem. Some hadn't known of services offered by the library. This behavior was representative of information retrieval problems faced by participants: they struggled in their efforts to obtain information, not to become expert library users.

Second, participants believed that librarians had no expertise in their area of interest, nor were they familiar with black scholars. They thought that librarians were disinterested in and disrespectful of minority-related research. Since many participants already felt like second-class citizens in the classroom and in their departments, they were not going to validate their negative feelings by going to a librarian and so avoided the library made their lives less stressful.

\section{Staying in the Comfort Zone}

Because students rarely used the librarian's services, which might have provided the opportunity to learn about new sources, they repeatedly used the sources with which they were familiar. They stayed in a limited space of familiar resources, rarely sought new ways of approaching a topic, and preferred a safe space by obtaining information from non-judgmental students, even students outside of their discipline, rather than risk a librarian's judgment of their library skills or research interests.

Another reason students do not use the library or librarians may be their need for 'just enough' information (Katopol, 2007). Information professionals may recoil at the idea that students let time rather than the nature of the information need determine the amount of search and retrieval performed for any given information task. Yet it is important to consider the complex and dynamic environment in which graduate students work. They have to meet the demands of many persons and organizations, demands that often occur simultaneously, such as the end of the semester grading as TAs and the need to submit their papers for their own classes. These demands, to get the work done, to turn in the paper, to record grades, etc., are often more important to the student than the more intellectual or academic consideration of obtaining all information possible on a topic (Katopol, 2007).

Preferring "just enough" information also has an effect on individual information management. While some students saved their search results for subsequent use on a similar topic, other students had no time for information management. This meant that each task required finding information anew, even though the time for search was limited. These students, like students everywhere, also used information gleaned from searches performed by other students. This can be problematic, as such behavior reduces the chance of encountering new and perhaps more useful information. Certainly education has canonical literature which students will use repeatedly; however, new information sources become available all the time. Education librarians, whose job it is to keep abreast of these sources, are much more likely to be able to recommend them to students than students are to find them on their own. However, if students will not consult with the librarian, whether from a false sense of security with preferred sources, or a reticence to work with a librarian, it is unlikely that they will find them at all.

\section{Is It Real or Is It Just Me? Race and Information Anxiety}

A continuous theme through participants' responses was that of race and how it was a factor as they attempted to meet their information needs. One way that race was a factor was in how students saw themselves through the eyes of others. In developing the concept of stereotype threat, Steele (1999) suggests that it is "the threat of being viewed through lens of a negative stereotype, or the fear of doing something that 
would inadvertently confirm that stereotype" (46). Like many students, regardless of race, black students may feel embarrassed when they have to admit they don't know something and need to ask for help. However, black students carry the additional burden of wondering if others will see their questions and insecurities as arising from incompetence. The black student might think that simply by asking questions, others might think that $\mathrm{s}$ /he does not belong in a graduate program. Stereotype threat is a powerful force constraining the actions and interactions of black students as well as other populations. Since its introduction, stereotype threat has been shown to affect the behaviors of Latino women (Gonzales, , Blanton, \& Williams, 2002); women (Murphy, Steele, \& Gross, 2007; Good, Aronson, \& Harder, 2008); and even white males in math classes vis-à-vis Asian students (Aronson, Lustina, Good, Keough, Steele, \& Brown, 1999). In information behavior, it may manifest itself as a burden on black students to know it all, to find all needed information on their own, and to be competent in their discipline to an extent not expected of nonminority students.

For black students in majority institutions, stereotype threat is a constant companion and source of stress, affecting their dealings with librarians as well as faculty, staff, and even other students. From being the only black person at a departmental event, to being unable to share your research interests with other students, to not being considered as a serious scholar either due to your race or your research interests, black students in majority institutions face a constellation of racially-oriented problems, of which information anxiety is only a part. As one participant put it, "When I talk about such issues [topics related to black concerns], I feel like all the time that I'm educating rather than getting something back." This attitude was seen across participants. The racial climate also caused some students to consider what they said and to whom, especially in regards to problems they may have within the program: "Trying to figure out who you can trust, who you can't is more difficult. You hope that you haven't already said something to somebody that you shouldn't have." There is little reason to share insecurities about one's work or questions about information needs when one fears that simply asking a question may end up negatively affecting progress in the program.

There are two factors, one based in reality and one based on perception, may prohibit the minority student / novice researcher from meeting his or her information needs. First, majority librarians may actually be unfamiliar with minority research issues and scholars. Education is a broad and dynamic field and not every librarian or every subject specialist will be familiar with every aspect of it. Second, black students believe that librarians are unfamiliar with minority research issues. Whether reality or perception, the effect is that the student does not include a librarian in information tasks. Consider this comment as a participant recounted the frustration stemming from attempting to work with a librarian, "I'm like 'You're a librarian, you've been here awhile, you know the system, you know my discipline. I'm not new in this [research area], I'm not breaking ground in any kind of way, but you don't seem to know anything I'm asking you, I find that to be hard to believe but yet you still have a job, amazingly.' Yeah, I was very frustrated. I was frustrated because I spent several hours getting nowhere. After that another minority student told me a secret, which was don't waste your time at the library - here's the person, you email this person, and that's it."

This level of dissatisfaction with library staff's ability to handle their sometimes unique information needs may lead black graduate students to, at best, avoid the library, and at worst, to believe that the librarians were overtly trying not to work with them. A combination of stereotype threat and a general feeling of unease may lead to the sense that one was "wasting time" trying to work with a librarian. 


\section{Summary}

The electronic and human information resources that graduate students use for academic tasks suggest that the concept of library anxiety should be usefully reframed into one of information anxiety. Most of the graduate students who participated in this study had a working grasp of the library's basic functions, so that the physical structure of the library or disturbing the librarian was not their greatest concern. Rather, the participants' anxiety arose from issues regarding online information: 1) finding too much information, so that they spent a lot of time determining relevance; 2) not finding enough information, so that it was difficult to do research; and 3) determining authenticity and authority of the online sources. When working with human sources of information, anxiety arose when students had to seek out information from people (librarians and faculty) who knew little about research on minority populations and when they felt that neither professors nor fellow students treated them as serious academics. These concerns were exacerbated by comments that participants took as a personal affronts, such as "How did you find that source?" (emphasis added by participant). Knowing that they would have to share their findings with others increased information anxiety at the search stage, especially as to the quality and quantity of the retrieved information. While most graduate students have moments of uncertainty during their program; these findings suggest that participants' uncertainty arises as much from anxiety over how their information will be received by others, and whether that reception will be tainted by racial stereotypes. The perception that faculty and library staff lack interest and expertise in research related to minorities is not seen simply as a difficulty to be overcome by one's own efforts, but as invalidating participants' research interests. Why should others listen to them if it is clear from the institutional atmosphere that their work is not valued? Thus, every aspect of participants' information behavior can be a cause of information anxiety.
At a time in their academic career when students are tasked with doing most work on their own, when they may be most in need of a relationship with a librarian, they have not forged that critical contact. Although willing to shoulder the burdens of being a minority scholar, they may find that in the end, the burden becomes intolerable and is better left behind. The viable option becomes leaving school without the degree, despite coursework success.

\section{Limitations and Suggestions for Future}

This study has limitations that affect its applicability to other black graduate students. First, the study is exploratory only and limited to fewer than ten students. While the responses provide an indication of the information behaviors of other similarly situated students, the findings cannot be applied to all black graduate students. There may have been too few participants to determine whether there was no new information to be gained from interviewing additional participants. Perhaps there are other methods of satisfying information needs that did not become apparent in the present study.

When researching visible minorities on a majority campus, it may be very difficult to obtain participants, especially where these students are the sole, or one of a very few, visible minorities in their department and do not wish to bring attention to themselves. Qualitative research elicits some very strong responses from participants, which adds depth to the findings, but it may be useful to employ a mixed methods approach in a future study. Using a small number of on-campus participants as a focus group and sending surveys to black student groups on other campuses should obtain a much wider range of responses and aid in determining whether the study's findings are true for students at other schools. In addition, researchers must be careful not to lump all minorities into one population for study. Blacks, Hispanics, and Asians have significantly different histories in the United States and the differences among various minority groups should be respected as we try to learn more about their information behaviors. 
Despite the study's limitations, it is consistent with the findings of an unpublished study from 2002 (Katopol). In that study, black graduate students from various disciplines at "University Y" (the pseudonym of a large, RU/VH, Research University, very high research activity)) were asked a series of questions about their information gathering behavior with the intent to learn about library anxiety and this population. Like students in the current study, participants at University Y overwhelmingly used the internet to search for information, and preferred online resources, whether owned or controlled by the university library or not, rather than go to the library. Time was again the primary constraint in participants' information behavior, as participants had families and work commitments that they stated reduced the amount of time they could spend on campus and in the library. These students preferred to use previously successful sources and search terms and did not make an effort to learn about new sources or more effective search methods, despite stating that they knew they "should" try to find all relevant sources. Participants explicitly stated that they were hesitant to seek help from a librarian out of a concern as to whether library staff would think they were "stupid" or didn't know how to use the library. When the previous findings are compared to the present study, the findings are very similar and suggest that this issue be revisited not just for students in one discipline, but for students across disciplines.

\section{Conclusion}

In many ways, black graduate students are no different from other graduate students. They have the same needs for the same types of information as others, they have to find information in the same places as other students, i.e. library resources, human resources as well as electronic resources that are not controlled by the library. They have the same need to be respected as persons and as new members of the academic community. They have the same need to have others show interest in their research and to respect it.
Information professionals working in education libraries cannot erase students' perceptions about race that have been cultivated over generations. It is worthwhile, however, for people who interact with students who struggle with anxieties and stressors that stem from being a minority in a majority environment to recognize the existence of these stressors and perceptions that affect whether and how these students will work with librarians. It might be useful for librarians in institutions with graduate programs to work with faculty and minority students to develop collections that reflect research interests of and research produced by minority scholars, if they do not do so already. In addition, librarians might work more closely with the department to show students the variety of resources and help them become more comfortable with them. They might also use course syllabi to become more familiar with the field.

Despite the struggles that may occur as they try to meet their information needs, these students saw themselves as certain of their abilities, steadfast in the pursuit of their research, and open to sharing their information experiences with similar students. This initial look into the entirety of black graduate students' information behavior indicates the complexity of needs which prompt the behavior, behavior which often occurs outside of the library's boundaries and suggests that information anxiety should be the continuing focus of research.

\section{References}

Aronson, J., Lustina, M. J., Good, C., Keough, K., Steele, C. M., \& Brown, J. (1999). When white men can't do math: Necessary and sufficient factors in stereotype threat.

Journal of Experimental Social Psychology, 35, 29-46.

Council of Graduate Schools. (2008). Ph.D. completion and attrition: Analysis of baseline demographic data from the Ph.D. Completion Project. Retrieved from http://www.phdcompletion.org/information Executive Summary Demographics_Boo k II.pdf 
Gonzales, P. M., Blanton, H., \& Williams, K. J. (2002). The effects of stereotype threat and double-minority status on the test performance of Latino women. Personality and Social Psychology Bulletin, 28, 659670.

Good, C., Aronson, J., \& Harder, J. A. (2008). Problems in the pipeline: Stereotype threat and women's achievement in high-level math courses. Journal of Applied Developmental Psychology, 29, 17-28.

Jiao, Q., \& Onwuegbuzie, A. (1997). Antecedents of library anxiety, Library Quarterly, 67(4), 372-389.

Jiao, Q., \& Onwuegbuzie, A. (1998).

Perfectionism and library anxiety among graduate students. Journal of Academic Librarianship, 24(5), 365-371. doi: 10.1016/S0099-1333(98)90073-8

Katopol, P. (2007). "Just Enough" information: Information behaviour, organizational culture, and decision making in municipal government. Canadian Journal of Information and Library Science-Revue Canadienne Des Sciences De L Information Et De Bibliotheconomie, 31(34), 233-247.

Katopol, P. (2005). Library anxiety. In K. Fisher, S. Erdelez \& L. Mckechnie (Eds.), Theories of information behavior (pp. 235238). Medford, NJ: Information Today.

Katopol, P. (2002). Library anxiety and black graduate students in majority institutions: A complex problem in multiple contexts. Unpublished manuscript.

Mellon, C. (1986). Library anxiety: A grounded theory and its development. College \& Research Libraries, 47, 160-165.

Murphy, M., Steele, C., \& Gross, J. (2007). Signaling threat: How situational cues affect women in math, science, and engineering settings. Psychological Science, 18, 879-885.
Onwuegbuzie, A. and Jiao, Q. (2000). I'll go to the library later: The relationship between academic procrastination and library anxiety. College \& Research Libraries, 61(1), 45-54.

Pettigrew, K., Fidel, R., \& Bruce, H. (2001). Conceptual frameworks in information behavior. Annual Review of Information Science and Technology, 35, 43-78.

Rasmussen, J., Pejtersen, A. M., \& Goodstein, L.P. (1994). Cognitive systems engineering. New York: Wiley.

Steele, C. (1999, August). Thin ice: Stereotype threat and black college students. The Atlantic Magazine. Retrieved from http://www.theatlantic.com/issues/99aug/9 908stereotype.htm

U.S. Census Bureau. (2011). 2010 Census shows America's diversity. Retrieved from http://2010.census.gov/news/releases/opera tions/cb11-cn125.html

U.S. Census Bureau. (2009). United States Population Projections. Retrieved from http://www.census.gov/population/www/pr ojections/analytical-document09.pdf

U.S. Census Bureau. (2008). An older and more diverse nation by midcentury. Retrieved from http://www.census.gov/newsroom/releases/ archives/population/cb08-123.html

Vicente, K. (1999). Cognitive work analysis. Mahwah NJ: Lawrence Erlbaum Associates.

\section{Patricia Fields Katopol}

Assistant Professor

School of Library and Information Science

3068 Main Library

University of Iowa

Iowa City, IA 52242-1420

patricia-katopol@uiowa.edu 